\title{
Effects of Long Durations of RF-Magnetron Sputtering Deposition of Hydroxyapatite on Titanium Dental Implants
}

\author{
Ihab Nabeel Safi ${ }^{1}$ Basima Mohammed Ali Hussein ${ }^{2, \odot}$ \\ ${ }^{1}$ Department of Prosthodontics, College of Dentistry, University of \\ Baghdad, Baghdad, Iraq \\ 2Department of Biomedical Applications, Institute of Laser for \\ Postgraduate Studies, University of Baghdad, Baghdad, Iraq \\ Eur J Dent 2021;15:440-447
}

Hikmat J. Aljudy ${ }^{1}$ Mustafa S. Tukmachi ${ }^{1}$

\begin{abstract}
Address for correspondence Basima Mohammed Ali Hussein, PhD, Department of Biomedical Applications, Institute of Laser for Postgraduate Studies, University of Baghdad, Baghdad 00964, Iraq (e-mail: yasbasima@yahoo.com).
\end{abstract}

\section{Abstract \\ Keywords \\ - dental implant \\ - field emission scanning electron microscopy \\ - hydroxylapatite \\ - magnetron sputtering \\ - titanium \\ - Vickers hardness}

Objectives Dental implant is a revolution in dentistry; some shortages are still a focus of research. This study use long duration of radiofrequency (RF)-magnetron sputtering to coat titanium ( $\mathrm{Ti}$ ) implant with hydroxyapatite (HA) to obtain a uniform, strongly adhered in a few micrometers in thickness.

Materials and Methods Two types of substrates, discs and root form cylinders were prepared using a grade 1 commercially pure (CP) Ti rod. A RF-magnetron sputtering device was used to coat specimens with HA. Magnetron sputtering was set at $150 \mathrm{~W}$ for 22 hours at $100^{\circ} \mathrm{C}$ under continuous argon gas flow and substrate rotation at $10 \mathrm{rpm}$. Coat properties were evaluated via field emission scanning electron microscopy (FESEM), scanning electron microscopy-energy dispersive X-ray (EDX) analysis, atomic force microscopy, and Vickers hardness (VH). Student's $t$-test was used.

Results All FESEM images showed a homogeneous, continuous, and crack-free HA coat with a rough surface. EDX analysis revealed inclusion of HA particles within the substrate surface in a calcium (Ca)/phosphorus (P) ratio (16.58/11.31) close to that of HA. Elemental and EDX analyses showed $\mathrm{Ca}, \mathrm{Ti}, \mathrm{P}$, and oxygen within Ti. The FESEM views at a cross-section of the substrate showed an average of $7 \mu \mathrm{m}$ coat thickness. Moreover, these images revealed a dense, compact, and uniform continuous adhesion between the coat layer and the substrate. Roughness result indicated highly significant difference between uncoated $\mathrm{Ti}$ and HA coat ( $p$-value $<0.05)$. A significant improvement in the $\mathrm{VH}$ value was observed when coat hardness was compared with the Ti substrate hardness ( $p$-value $<0.05$ ).

Conclusion Prolonged magnetron sputtering successfully coat Ti dental implants with HA in micrometers thickness which is well adhered essentially in excellent osseointegration.

\section{Introduction}

Hydroxyapatite (HA) and $\beta$ tricalcium phosphate are acceptable bioactive materials because of their apatite formation abilities. ${ }^{1-3}$ The inorganic $\mathrm{HA}, \mathrm{Ca}_{10}(\mathrm{PO} 4)_{2}(\mathrm{OH})_{2}$, is an essential biomaterial component of human hard tissues as bones and teeth. Owing to its inherent biocompatibility, it is used for medical and dental implant coatings. ${ }^{4,5}$ The

published online

January 28, 2021
DOI https://doi.org/

10.1055/s-0040-1721314 ISSN 1305-7456. role of a coating material is to protect the body organs from metal ions that may be released by metallic implant materials. Moreover, the ability to induce implant a bone bonding is an important factor to consider when selecting a coating material. Hence, the coating material should be pore free, dense, and with a strong adhesion to their substrate material. ${ }^{6,7}$ Metal surfaces can be coated by bioactive

(C) 2021. European Journal of Dentistry.

This is an open access article published by Thieme under the terms of the Creative Commons Attribution-NonDerivative-NonCommercial-License, permitting copying and reproduction so long as the original work is given appropriate credit. Contents may not be used for commercial purposes, or adapted, remixed, transformed or built upon. (https://creativecommons.org/licenses/by-nc-nd/4.0/)

Thieme Medical and Scientific Publishers Pvt. Ltd., A-12, 2nd Floor, Sector 2, Noida-201301 UP, India 
materials via several methods, such as, dip coating, electrophoretic deposition, thermal sputtering, colloidal solution deposition, magnetron sputtering, plasma spraying, sol-gel technique, and pulsed laser deposition, to enhance bone healing and metal implant integration.

Coating thickness is a crucial factor that will determine the success or failure of a direct implantation procedure. The aforementioned implantation methods can achieve a coating thickness ranging from 0.05 to $200 \mu \mathrm{m} .{ }^{8}$ For instance, sand blasting with an acid provides a coat with numerous micropores on the substrate surface to stimulate bone growth. However, this technique requires a healing period of $\sim 3$ to 6 months. ${ }^{9}$ A commonly applied method is plasma-sprayed coating of implant surface using HA to improve biocompatibility and rapid bone tissue growth. ${ }^{10}$ However, this technique has several disadvantages, such as it produces a thick HA coating layer ranging from 75 to $150 \mu \mathrm{m} .{ }^{11}$ Shortages of this coat leads to delamination a adhesion and cohesion failure with porosity, ${ }^{12}$ as well as a decrease in the ability of the coat to withstand shear fatigue. ${ }^{13}$ These coat thickness-related complications can result in implant failure due to breakage of the coating film. The radiofrequency (RF) sputtering technique is an alternative method that involves collision of high-energy electrons with gas molecules or atoms to form positive ions for bombarding the HA target after ionization and excitation-relaxation reaction, which in turn deposit the target material onto the implant substrate material. ${ }^{14} \mathrm{RF}$-magnetron sputtering provides elemental composition coating by sintering the target made from a homogeneous mixture of phosphates to provide high-purity coating. ${ }^{15}$ This method provides very thin coat (nanoscale films); a thin coat may degrade rapidly, a condition that is detrimental to dental implants. ${ }^{1,16,17}$ Therefore, the objective is to create thick, well-adhered HA coat that allow sufficient time for osseointegration and will not easily separate during the procedure. A coating of HA in a few micrometers in thickness is ideal because such coating may not exfoliate as rapidly as thinner or thicker HA coatings. ${ }^{18,19}$

This study used long durations of RF-magnetron sputtering deposition to produce a microscale HA bioceramic layer and evaluated its effects on grade 1 commercially pure (CP) titanium (Ti) implant materials.

\section{Materials and Methods}

\section{Sample Preparation}

Grade 1 CP Ti (99.9\% purity) (Baoji Jinsheng Metal Material, China) supplied as annealed rods with a dimension of $1,000 \mathrm{~mm} \times 6 \mathrm{~mm}$ (length $\times$ diameter) were used to prepare the substrate. Two different substrate specimens were prepared: a disc-shaped specimen with a dimension of $6 \mathrm{~mm} \times 2 \mathrm{~mm}$ (diameter $\times$ thickness) was prepared by cutting the Ti rods using a water jet machine; the other was a cylindrical specimen (root form implant) with a dimension of $3 \mathrm{~mm} \times 6 \mathrm{~mm}$ (diameter $\times$ length) that was fabricated using a turning machine, to demonstrate that this technique applicable for every implant surface design, root or screw. The disc specimens were used for in vitro coating optimization and characterization, whereas the cylindrical specimens were utilized for in vivo biomechanical and histological evaluations. Before sputtering, all specimens were gradually polished using a silicon carbide ( $\mathrm{SiC}$ ) polishing paper with increasing grit sizes of 500, 800, 1,200, 2,000, and 2,400 . The specimens were cleaned with absolute ethanol in an ultrasonic cleaning device for 30 minutes and then air dried. The specimens were etched using a solution of distilled water, $6 \% \mathrm{HNO}_{3}$ and $2 \% \mathrm{HF}$ for 3 minutes to remove the oxide layer. After etching, the specimens were rinsed with acetone for coating. ${ }^{20,21}$ A custom-made stainless steel plat holder was designed to hold the circular substrates and fix the rod substrates (root form) vertically in the vacuum chamber during sputtering to ensure uniform coating.

\section{Hydroxyapatite Target Preparation}

The targets for magnetron sputtering $(50 \mathrm{~mm} \times 3 \mathrm{~mm}$, diameter $\times$ thickness) were custom fabricated and sintered from HA powder $(99.99 \%$ purity, the particle size was > $30 \mathrm{~nm}, \sim 2.13 \mathrm{~g} / \mathrm{cm}^{3}$ in density, and had a stoichiometric calcium $[\mathrm{Ca}] /$ phosphorus $[\mathrm{P}]$ ratio of 1.6). The targets were produced by vacuum hot-press sintering (Jiangyin Entret Coating Technology Co.). The pressure was $50 \mathrm{MPa}$, and the sintering temperature was $1,100^{\circ} \mathrm{C}^{22}$ A protective copper cover was used to protect the targets from cracks during sputtering process because the power of a device suddenly breakdown to zero when plasma strikes to the broken area (cracks) of the target as sparking occurs in that area.

\section{Sputtering Process}

Several sputtering trials were conducted in a pilot study to determine the suitable sputtering parameters for optimal coating deposition for 90 minutes. A magnetron sputtering device (Torr International Inc., United States) was used with different parameters, including magnetron power, working pressure, and target-to-substrate distance (-Table 1 and - Fig. 1 ). Thickness was calculated at six different target-to-substrate distances $(20,30,40,50,60$, and $70 \mathrm{~mm}$ ) for each specific magnetron power that was used. The optimum sputtering parameters were identified by measuring coat thickness on a square quartz microscope slide $(25.4 \mathrm{~mm} \times 25.4 \mathrm{~mm} \times 1 \mathrm{~mm}$ thick; Ted Pella, Inc., United States) using a laser ellipsometer (SE 800, Sentech, Germany). The quartz slides provide extremely high purity, optical, and ultraviolet transparency, all these are important when a laser ellipsometer was used to measure coat thickness.

\section{Final Coating Process}

The results of the pilot study showed that sample D was the best sample to obtain the optimum coat. Its sputtering parameters are listed in - Table $\mathbf{1}$.

The pressure of the sputtering chamber was set to less than $1.5 \times 10^{-5}$ Torr as the base pressure, and the working pressure was set $1.5 \times 10^{-3}$ Torr. Argon gas was then introduced into the device as sputtering gas at a flow rate of $150 \mathrm{~cm}^{3} / \mathrm{min}$. The coating process was performed by RF sputtering at a 
Table 1 Sputtering process parameters

\begin{tabular}{|c|c|c|c|c|c|}
\hline Sample & $\begin{array}{l}\text { Magnetron } \\
\text { power (W) }\end{array}$ & $\begin{array}{l}\text { Working } \\
\text { pressure (Torr) }\end{array}$ & $\begin{array}{l}\text { The } \\
\text { target-to-substrate } \\
\text { distance }(\mathrm{mm})\end{array}$ & $\begin{array}{l}\text { Coat } \\
\text { thickness (nm) }\end{array}$ & Observation results \\
\hline A & 100 & $3 \times 10^{-3}$ & $20-70$ & $90 \pm 11$ & \\
\hline B & 120 & $3 \times 10^{-3}$ & $20-70$ & $120 \pm 13$ & \\
\hline C & 130 & $3 \times 10^{-3}$ & $20-70$ & $180 \pm 19$ & \\
\hline $\mathrm{D}$ & 150 & $3 \times 10^{-3}$ & $20-70$ & $192 \pm 22$ & $\begin{array}{l}\text { Coat was uniform, dense, and } \\
\text { compact (- Fig. 1A, 1B) }\end{array}$ \\
\hline$E$ & $>150$ & & & & $\begin{array}{l}\text { Crack of the target and change in } \\
\text { stoichiometry }\end{array}$ \\
\hline $\mathrm{F}$ & $<100$ & & $>70$ & & $\begin{array}{l}\text { Coat was delaminated, adhesive } \\
\text { and cohesive failure with porosity } \\
\text { (- Fig. 1C, 1D) }\end{array}$ \\
\hline
\end{tabular}
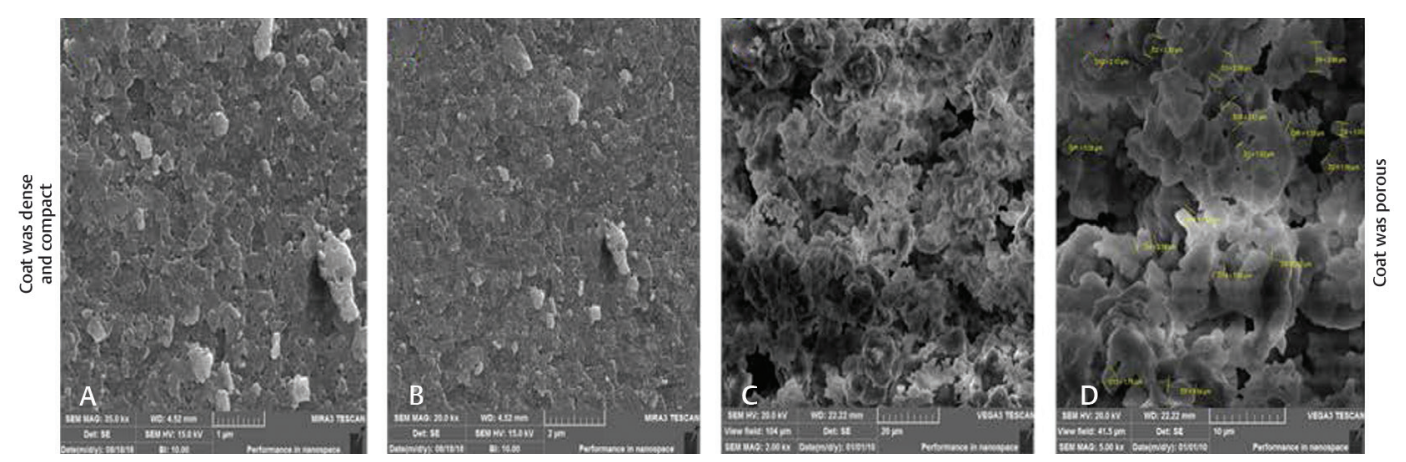

Fig. 1 FESEM images for substrates surfaces after sputter processing (A, B) as a function of sputter at power level of $150 \mathrm{~W}$ and the target-to-substrate distance was $40 \mathrm{~mm}(\mathbf{C}, \mathbf{D})$ as a function of sputter at power level of $70 \mathrm{~W}$ and the target-to-substrate distance was $80 \mathrm{~mm}$. FESEM, field emission scanning electron microscopy.

power level of $150 \mathrm{~W}$. During sputtering, the magnetron power applied to the targets was gradually increased by $10 \mathrm{~W}$ every 3 minutes and maintained at $150 \mathrm{~W}$ until the end of the sputtering process. The deposition heat was fixed at $100^{\circ} \mathrm{C}$; the temperature of the substrate during the sputtering procedure was $100^{\circ} \mathrm{C}$. During the sputtering process, water was ejected to cool the targets. The entire procedure (deposition time) lasted for 22 hours to obtain a coat more than $5 \mu \mathrm{m}$ in thickness. The substrates were moved in a rotary motion during deposition at $10 \mathrm{rpm}$. The target-to-substrate distance was 30 to $40 \mathrm{~mm}$. Afterward, all HA substrates were sintered in a sintering oven (Nabertherm, Sintering Furnace HTCT01-16, United States). The heat treatment was conducted in air, and the temperature was gradually increased by $10^{\circ} \mathrm{C} /$ min up to $550^{\circ} \mathrm{C}$ for 1 hour (-Fig. 2). ${ }^{23}$

The discs were molded vertically, and the yielded blocks were ground using a 400 grit $\mathrm{SiC}$ paper and then finished and polished with a 2,000 grit $\mathrm{SiC}$ paper to expose the substratecoat area. ${ }^{20,24}$

Coating thickness and surface morphology were investigated via field emission scanning electron microscopy (FESEM) (MIRA3 Tescan, Czech Republic). SEM-energy dispersive X-ray (EDX) analysis was conducted for elemental analysis. Elemental distribution was determined via EDX mapping. Vickers hardness (VH) test (Buehler Micromet 5103, United States) was performed to measure coat hardness.

\section{Results}

\section{Surface Microstructure}

Ti- and HA-coated substrates were examined via FESEM. The HA coating surface was continuous, crack free, and the HA particles were uniformly distributed with few aggregates of different sizes (-Fig. $\mathbf{3}$ ).

\section{Chemical Analysis of Ti and Hydroxyapatite-Coated Substrates}

EDX analysis of the control (uncoated) Ti surface revealed that the surface consisted of Ti and oxygen (O). By comparison, the analysis revealed the presence of HA particles on the surface of the HA-coated substrate and that it comprised of $\mathrm{Ca}, \mathrm{Ti}, \mathrm{P}$, and $\mathrm{O}$. Moreover, the coating was not contaminated by other elements ( - Table 2 ).

\section{Ca/P Ratio of Hydroxyapatite Coating}

The $\mathrm{Ca} / \mathrm{P}$ ratio in the coat layer $(16.58 / 11.31)$ was $\sim 1.5$ (-Table 2), which was close to that in $\mathrm{Ca}_{10}\left(\mathrm{PO}_{4}\right)_{6} \cdot 2 \mathrm{H}_{2} \mathrm{O}(10 / 6)^{25}$ because the $\mathrm{HA}$ target had a stoichiometric $\mathrm{Ca} / \mathrm{P}$ ratio 

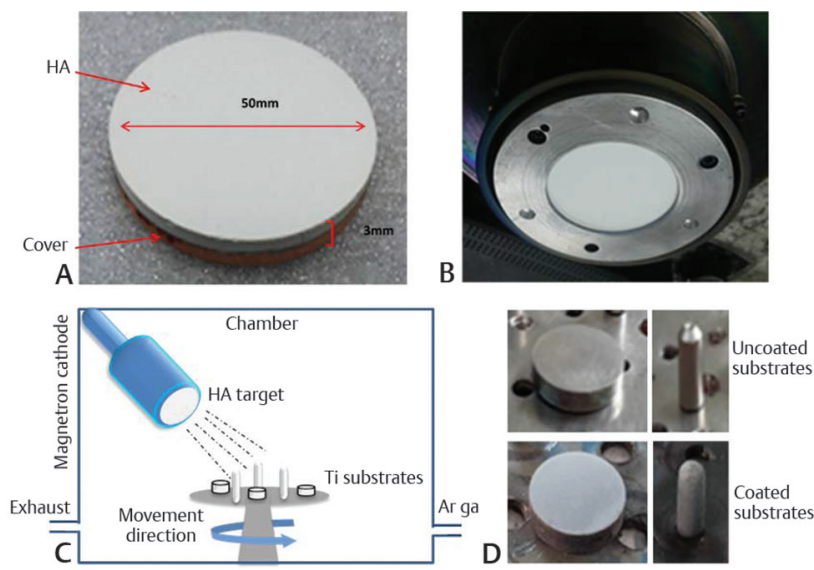

Fig. 2 (A) HA target, (B) holder of the target, (C) schematic diagram of experimental sputtering setup, and (D) Ti- and HA-coated substrates. HA, hydroxyapatite; Ti, titanium.
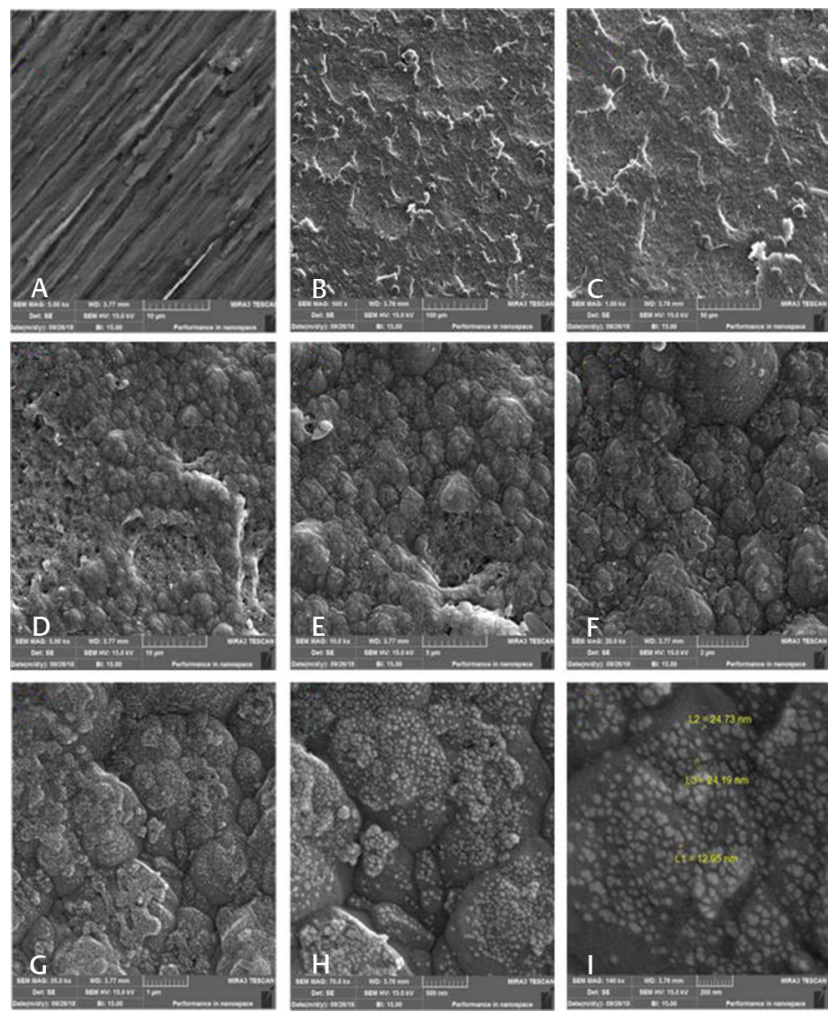

Fig. 3 FESEM surface topographic image: (A) uncoated Ti and (B-I) FESEM surface topographic images of coated substrate at different magnifications of $\times 500, x 1,000, \times 5,000, x 10,000, x 20,000, x 35,000, x 70,000$, and $x 140,000$. FESEM, field emission scanning electron microscopy; Ti, titanium.

Table 2 EDX results of the coated substrate

\begin{tabular}{|l|l|l|}
\hline Element & Mass\% & Atom\% \\
\hline $\mathbf{O}$ & 52.43 & 71.60 \\
\hline $\mathbf{P}$ & 16.04 & $\mathbf{1 1 . 3 1}$ \\
\hline $\mathbf{C a}$ & 30.41 & $\mathbf{1 6 . 5 8}$ \\
\hline $\mathbf{T i}$ & 1.13 & 0.51 \\
\hline & 100 & 100 \\
\hline
\end{tabular}

Abbreviations: Ca, calcium; EDX, energy dispersive X-ray; O, oxygen; P, phosphoru s; Ti, titanium. of 1.6. Therefore, RF-magnetron sputtering did not alter the $\mathrm{Ca} / \mathrm{P}$ ratio (-Fig. 4).

The cross-section line elements at the HA-Ti interface were analyzed via EDX line scans of the interface at different areas (-Fig. 5).

EDX elemental analysis of the coat area revealed abundant $\mathrm{Ca}, \mathrm{P}$, and $\mathrm{O}$ atoms in the coating. EDX elemental analysis showed that the interface consisted of $\mathrm{Ti}, \mathrm{Ca}, \mathrm{P}$, and $\mathrm{O}$ atoms. EDX elemental analysis revealed that the Ti substrate comprised abundant Ti atoms. From the Ti substrate area to the coating area, the EDX line scans showed that the levels of $\mathrm{Ca}$ and $\mathrm{P}$ increased and that of Ti decreased.

\section{Coat Thickness and Interface Microstructure}

The average thickness of the coating layer was $7 \mu \mathrm{m}$ ( - Fig. 6). FESEM images of the interface showed that the Ti substrate embedded the HA particles well such that the HA particles were trapped on the surface layer of Ti and bonded (no gap) with the Ti substrate. The thickness of $7 \pm 0.9 \mu \mathrm{m}$ was obtained as a result of long sputtering time of 22 hours at $150 \mathrm{~W}$. A coating thickness of 1 to $50 \mu \mathrm{m}$ does not affect the fatigue strength of the substrate. ${ }^{11}$ Aside from the problems commonly encountered by various coating techniques, a study reported that coating with pure HA results in poor adhesion with the substrate and deterioration of several mechanical properties over time when the coating is immersed in simulated body fluids. ${ }^{26}$ The FESEM image showed that the coat layer was highly uniform, dense, and compact, without visible defects (microcracks and pores) and with good adhesion to the Ti substrate ( - Fig. $\mathbf{6}$ ).

EDX mapping of the cross-section of the substrate showed that the HA particles were embedded in the Ti substrate at the interface area with no gaps ( - Fig. 7). Elemental analysis of the deep structure (not the interface line) of a typical cross-section of the HA-coated and Ti interfaces revealed the presence of $\mathrm{Ca}$ and $\mathrm{P}$, which are the main elements of HA.

\section{Surface Roughness}

In this study, three-dimensional roughness parameters (nm) were investigated via atomic force microscopy (Nanoscope, California, United States). The mean values of five substrates were each tested at three different positions ( - Table 3 ). The HA coat of Ti had surface roughness significantly higher than uncoated Ti substrates.

\section{Vickers Hardness of the Coating}

The mean values of the hardness of the HA-coated Ti substrate was $(1,118 \mathrm{VH})$, which was significantly higher than that of the Ti substrate (266.7 VH). The difference between the coated and uncoated substrates was highly significant ( $p$-value $<0.05 ;-$ Fig. 8 and $\sim$ Table 4 ).

\section{Discussion}

A common limitation of metallic implants is its inability to pair harmoniously with the surrounding bone. This mismatch between metallic implants and human bones is 

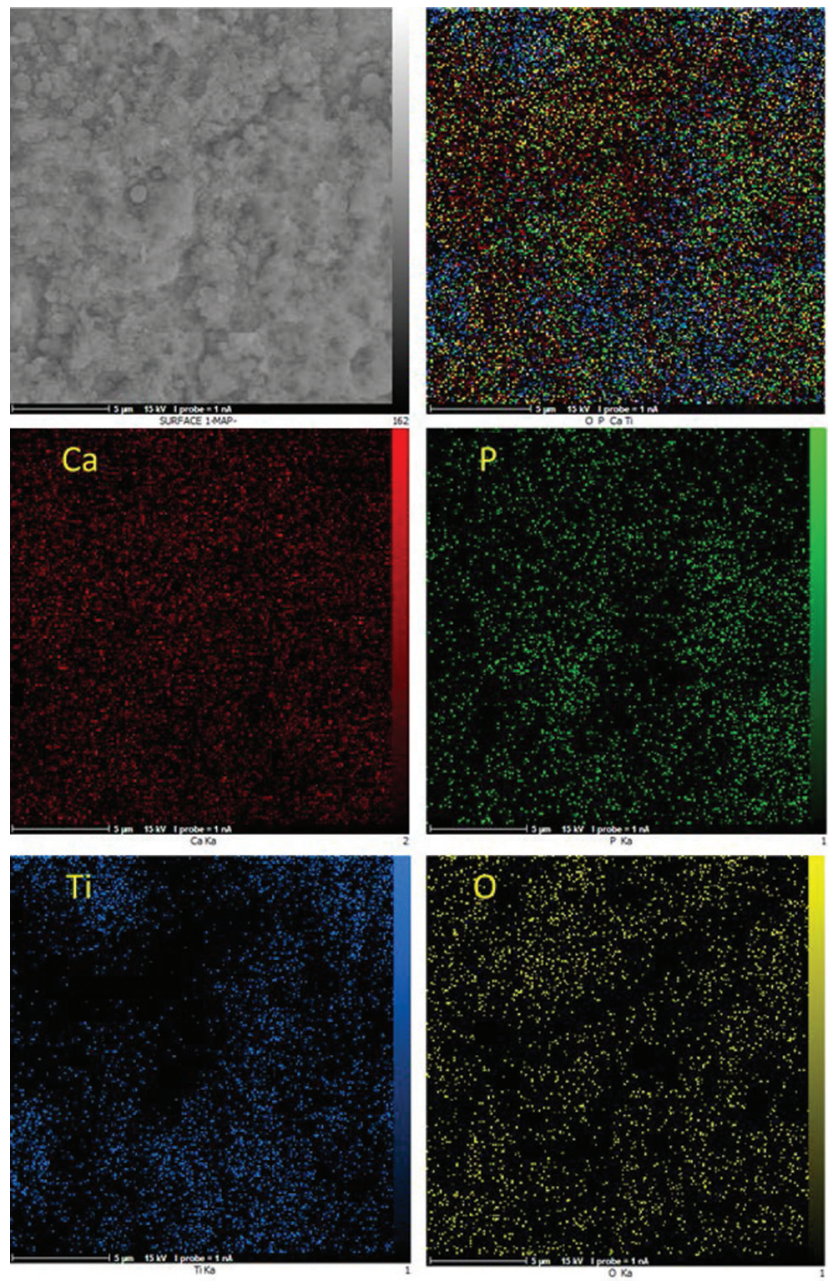

Fig. 4 SEM-EDX maps of coated Ti substrate surface. SEM-EDX, scanning electron microscopy-energy dispersive X-ray; Ti, titanium.
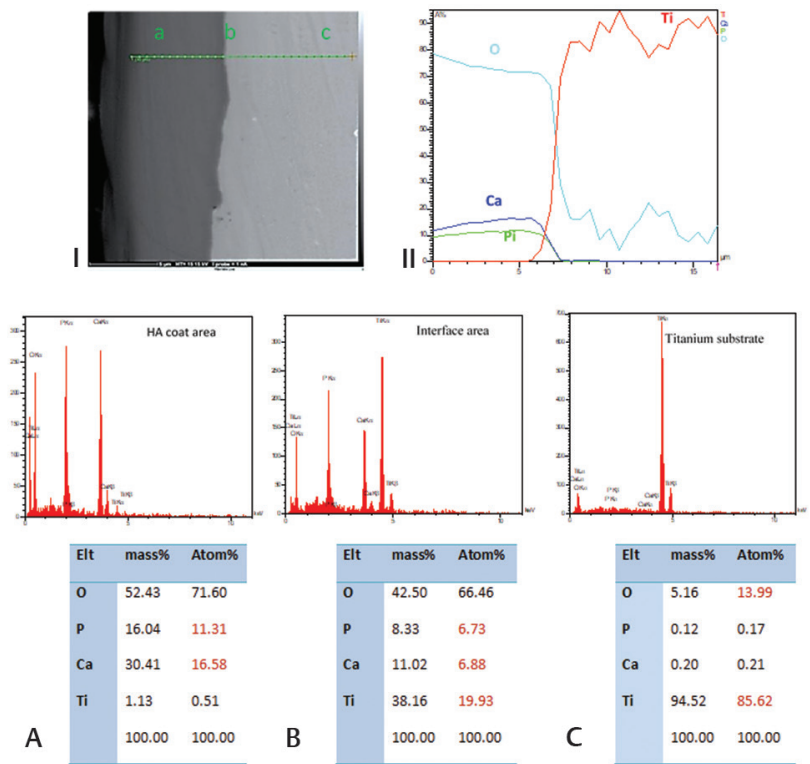
Elt mass\% Atom\% $\begin{array}{lll}0 & 5.16 & 13.99\end{array}$
$\begin{array}{lll}\text { p } & 0.12 & 0.17\end{array}$
Ca $\quad 0.20 \quad 0.21$
$\pi \quad 94.52 \quad 85.62$
C $\quad 100.00 \quad 100.00$

Fig. 5 (I) FESEM cross-section image of the coat, (II) EDX compositional line scan data of the Ti-HA layer interface at the selected areas; (A) HA coat, (B) interface, and (C) Ti substrate. EDX, energy dispersive $\mathrm{X}$-ray; FESEM, field emission scanning electron microscopy; HA, hydroxyapatite; Ti, titanium.

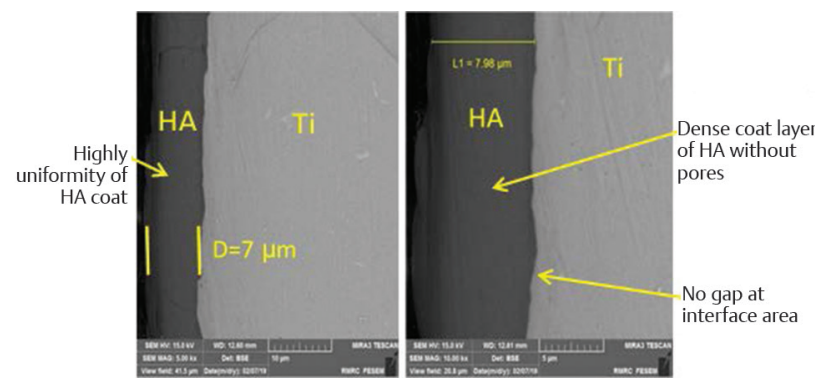

Fig. 6 FESEM images of cross-section substrate at Ti-HA interface area at the sputtering power of $150 \mathrm{~W}$ for 22 hours, at different magnifications of 5,000 and 10,000. FESEM, field emission scanning electron microscopy; HA, hydroxyapatite; Ti, titanium.
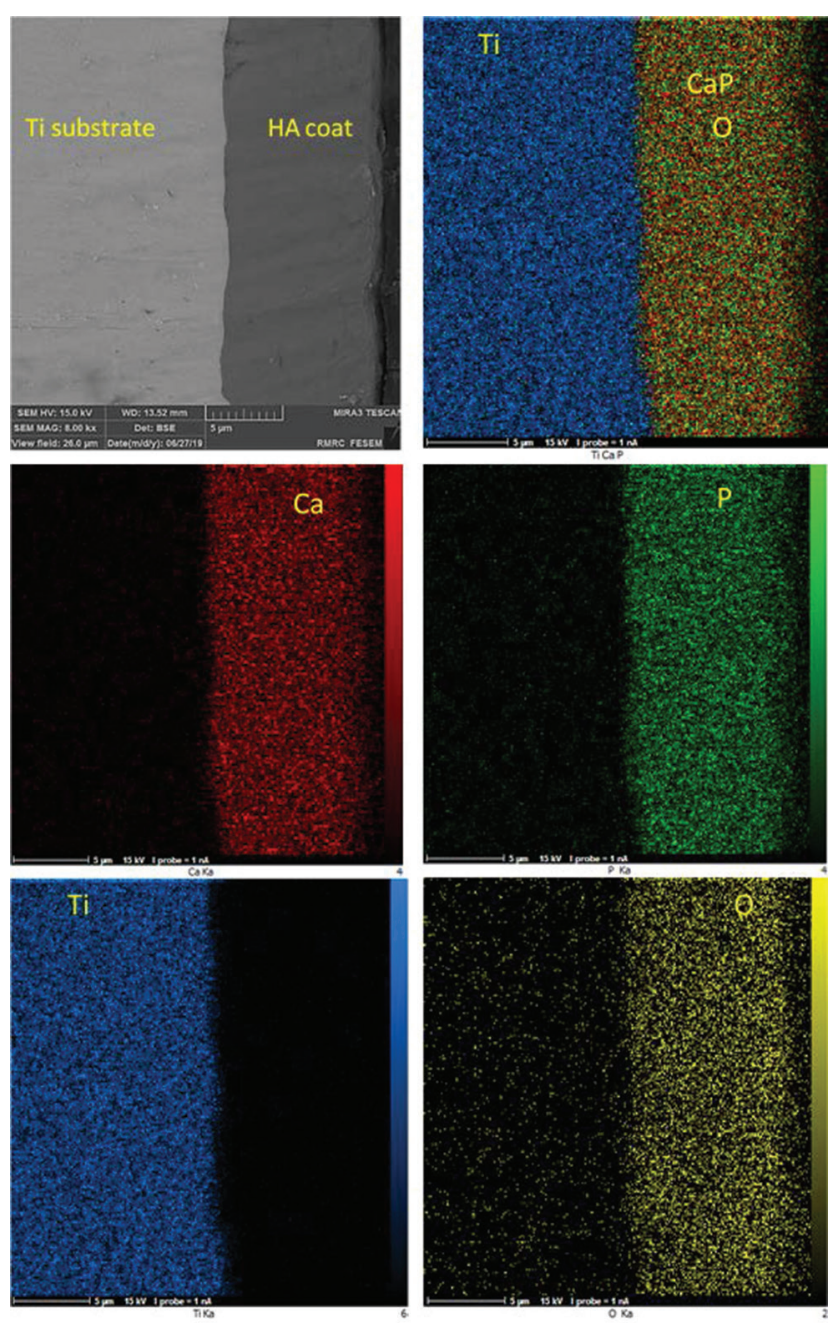

Fig. 7 SEM-EDX maps of HA-coated cross-section Ti substrate surface. HA, hydroxyapatite; SEM-EDX, scanning electron microscopyenergy dispersive $\mathrm{X}$-ray; $\mathrm{Ti}$, titanium.

attributed to differences in chemical compositions of the two materials. A surface modification commonly applied to address this problem is coating the implant with a bioactive material, such as HA, with a chemical composition similar to that of bone. Surface coating proves to be successful in enhancing osseointegration and controlling the limitations of metal-based implants, such as corrosion, wear, and release 
Table 3 Topographic analyses roughness (nm) of the Ti substrate and HA coat

\begin{tabular}{|l|l|l|l|l|}
\hline Substrates & $\mathrm{S}_{\mathrm{a}}(\mathrm{nm})$ & $\mathrm{S}_{\mathrm{dr}}(\%)$ & $\mathrm{S}_{\mathrm{dq}}\left(/ \mathrm{nm}^{2}\right)$ & $\mathrm{S}_{\mathrm{q}}(\mathrm{nm})$ \\
\hline Untreated $\mathrm{Ti}$ & $9.36 \pm 1.2$ & $0.5 \pm 0.06$ & $0.01 \pm 0.005$ & $0.27 \pm 0.03$ \\
\hline HA coat & $18.28 \pm 2.01$ & $3.07 \pm 0.1$ & $0.261 \pm 0.06$ & $3.69 \pm 0.4$ \\
\hline
\end{tabular}

Abbreviations: $\mathrm{HA}$, hydroxyapatite; $S_{\mathrm{a}}$, roughness average; $S_{d q}$, slop root mean square; $S_{d r}$, increment of the interfacial surface area relative to a flat plane baseline; $\mathrm{S}$, height root mean square of the surface; Ti, titanium.

Note: Result indicated highly significant difference between uncoated Ti and HA coat using $t$-test at $p$-value $<0.05$.

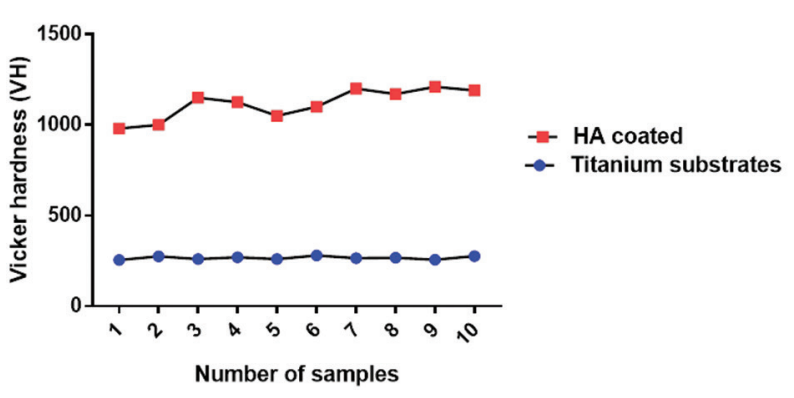

Fig. 8 Plot of $\mathrm{VH}$ values for control substrate and the HA-coated substrate. HA, hydroxyapatite; VH, Vickers hardness.

of harmful ions. ${ }^{27}$ Surface coating is the solution in dental implantology. A bioactive coat masks the adverse effects of metal surfaces (dental implants). A continuous and crackfree coat indicates positive biological interactions between living tissues and artificial substitutes.

The power was fixed according to the result of pilot study. When we used power more than $150 \mathrm{~W}$, this result in the crack of the target and change in stoichiometry. When we used power less than $100 \mathrm{~W}$, coat was delaminated, adhesive, and cohesive failure with porosity ( - Fig. 2C, 2D). The temperature was $100^{\circ} \mathrm{C}$ to improve the adhesion.

FESEM revealed that the roughness of the HA coating surface was favorable. This roughness is crucial in ensuring that the bone tissues and implants will bond, thereby enhancing osseointegration and improving the prognosis of implant treatments. ${ }^{19}$

The chemical integrity of HA affects its biocompatibility. The molar ratio of $\mathrm{Ca} / \mathrm{P}$ is a key indicator of $\mathrm{HA} .{ }^{25}$ Based on crystallographic analysis, the HA coat resembles natural bones in terms of chemical structure. Hence, the HA coat stimulates cell adhesion and improves cell anchorage.

This result indicated that HA was the main constituent phase in the coating. Moreover, the chemical composition of the coating material did not change during the sputtering process. Despite long sputtering time, the device power of $150 \mathrm{~W}$ did not induce HA to undergo thermal decomposition, a process that may affect its biocompatibility.

The whole section of the EDX map including the substrate and the coat revealed penetration of $\mathrm{Ca}$ and $\mathrm{P}$ indicates HA inclusion within the superfacial thickness of Ti. If this is correlated with dental implant applications, it enhances the bioactivity of Ti fixtures that in turn may help in osseointegration. ${ }^{28}$
In this study, coat layer thickness was measured from the cross-sectional FESEM images of Ti-coated specimens. A thick coating layer is beneficial that will allow sufficient time for osseointegration, but previous studies reported that the coating layer cracks when the thickness is 30 to 80 $\mu \mathrm{m}$. The optimal coat thickness to enhance osseointegration is 5 to $50 \mu \mathrm{m} .{ }^{29,30}$ To achieve the desired osteoconductive effect of HA coating and prevent cracking of the coating layer, researchers proposed an implant coating layer of only few micrometers in thickness. ${ }^{30,31}$ The excellent properties of the coat ensure proper fixture insertion during implantation without the coat crumbling. Furthermore, a dense, thin HA layer is more dissolution resistant than a porous, thick HA layer. ${ }^{32}$ The $7-\mu \mathrm{m}$-coated thickness is ideal because such coating may not exfoliate as rapidly as thinner or thicker HA coatings.

EDX mapping of the cross-section of the substrate, if this is correlated with dental implant applications, it enhances the bioactivity of $\mathrm{Ti}$ fixtures that in turn may help in osseointegration. ${ }^{28}$

Regarding implant surface roughness, increase surface roughness helps in mechanical interlocking for hard tissues. ${ }^{33}$ Such rough coating surfaces are advantageous because they enhance bonding to bone tissue in vivo. ${ }^{34,35}$ Applying bioactive ceramics and increasing roughness are the main causes to improve surface properties for Ti implants. Implant surface textures at values $<100 \mathrm{~nm}$ promoted cell adhesion and longevity, ${ }^{36}$ while surfaces textures decreased cell attachment at values $>100 \mathrm{~nm}$. Similar trends have been found in other studies using different cells. ${ }^{37}$ The removal torque values directly related to rough implant surface aid in mechanical interlocking and improve the surface area. ${ }^{33}$ The literature confirms that surface texture and chemistry are important. Other technique which has the same coating criteria is long durations of pulse laser deposition technique.

Surface roughness of the implant is another important factor, and high Vickers hardness indicates that the coat layer is less likely to degrade over time. When bones remodel at the implant site, the HA coating slowly degrades without loss of adhesion. The slow release of HA ions at the interface probably stimulates the formation of new bones. ${ }^{38,39}$ An extended osseointegration will result from slow resorption of implant coating and bone remodeling. Coated Ti dental implants were covered with three-layered cell sheets that successfully form using collagen grafts as a scaffold ${ }^{40}$ to construct biohybrid implants. 
Table 4 Descriptive statistic and t-test for hardness test in Vickers hardness number of the Ti substrate and HA coat

\begin{tabular}{|l|l|l|l|l|l|l|}
\hline Group & Minimum & Maximum & Mean & SD & $t$-test & $p$-Value \\
\cline { 1 - 3 } & 255 & 280 & 266.7 & 2.765 & 32.22 & $<0.0001(\mathrm{HS})$ \\
\cline { 1 - 2 } & 980 & 1,210 & 1,118 & 26.26 & & \\
\hline
\end{tabular}

Abbreviations: HA, hydroxyapatite; HS, highly significant; SD, standard deviation; Ti, titanium.

\section{Conclusion}

Magnetron sputtering can be used to coat Ti dental implants with HA. A desirable coat thickness can be safely achieved over a prolonged sputtering time of up to 22 hours. Proper coat adhesion and interconnection and suitable coat thickness and hardness can be achieved via magnetron sputtering. This technique is applicable for every implant surface design, root or screw.

\section{Conflict of Interest}

None declared.

\section{References}

1 Prosolov KA, Popova KS, Belyavskaya OA, et al. RF magnetron-sputtered coatings deposited from biphasic calcium phosphate targets for biomedical implant applications. Bioact Mater 2017;2(3):170-176

2 Jani GH, Al-Ameer SS, Jawad S. Histological and histomorphometric analysis of strontium chloride coated commercially pure titanium implant compared with hydroxyapatite coating. J Bagh College Dentistry 2015;27(1):26-31

3 Meyer F, Enax J. Hydroxyapatite in oral biofilm management. Eur J Dent 2019;13(2):287-290

4 Pichugin VF, Surmenev RA, Shesterikov EV, et al. The preparation of calcium phosphate coatings on titanium and nickel-titanium by RF-magnetron-sputtered deposition: composition, structure and micromechanical properties. Surf Coat Tech 2008;202(16):3913-3920

5 Ali AM, Thair L, Intisar J. Studying biomimetic coated niobium as an alternative dental implant material to titanium (in vitro and in vivo study) Baghdad Science Journal 2018;15(3):253-261

6 Daculsi G, LeGeros RZ, Heughebaert M, Barbieux I. Formation of carbonate-apatite crystals after implantation of calcium phosphate ceramics. Calcif Tissue Int 1990;46(1):20-27

7 Yonggang Y, Wolke JGC, Yubao L, Jansen JA. In vitro evaluation of different heat-treated radio frequency magnetron sputtered calcium phosphate coatings. Clin Oral Implants Res 2007;18(3):345-353

8 Smolina I, Szymczyk P, Chlebus E, Ivashchenko I, Kurzynowski T. Composite laser-clad coating on titanium substrate using pure hydroxyapatite powder. Powder Metall Met Ceramics 2015;54(5):318-323

9 Hung K-Y, Lai H-C, Feng H-P. Characteristics of RF-sputtered thin films of calcium phosphate on titanium dental implants. Coatings 2017;7(8):126

10 Aoki H, Marvelous Biomaterial Apatite. Tokyo: Ishiyaku Publishers, Inc; 1999

11 Lynn AK, DuQuesnay DL. Hydroxyapatite-coated Ti-6Al-4V part 1: the effect of coating thickness on mechanical fatigue behaviour. Biomaterials 2002;23(9):1937-1946
12 Gökmenoğlu C, Özmeriç N, Çakal G, Dökmetas N, Ergene C, Kaftanoglu B. Coating of titanium implants with boron nitride by RF-magnetron sputtering. Bull Mater Sci 2016;39(5):1363-1370

13 Callaghan JJ, Rosenberg AG, Rubash HE, Adult Hip. Vol II. Philadelphia, New York: Lippincott-Raven; 1998

14 Lai H-C, Tsai H-H, Hung K-Y, Feng H-P. Fabrication of hydroxyapatite targets in radio frequency sputtering for surface modification of titanium dental implants. J Intell Mater Syst Struct 2014;26(9):1050-1058

15 Chaikina MV, Pichugin VF, Surmeneva MA, Surmenev RA. Mechanochemical synthesis of hydroxyapatite with substitutions for depositing the coatings on medical implants by means of high-frequency magnetron sputtering. Chemistry for Sustainable Development 2009;17:507-513

16 Wan T, Aoki H, Hikawa J, Lee JH. RF-magnetron sputtering technique for producing hydroxyapatite coating film on various substrates. Biomed Mater Eng 2007;17(5):291-297

17 Surmeneva MA, Surmenev RA, Nikonova YA, et al. Fabrication, ultra-structure characterization and in vitro studies of RF magnetron sputter deposited nano-hydroxyapatite thin films for biomedical applications. Appl Surf Sci 2014;317:172-180

18 Jung U-W, Hwang JW, Choi DY, et al. Surface characteristics of a novel hydroxyapatite-coated dental implant. J Periodontal Implant Sci 2012;42(2):59-63

19 Łukaszewska-Kuska M, Krawczyk P, Martyla A, Hędzelek W, Dorocka-Bobkowska B. Hydroxyapatite coating on titanium endosseous implants for improved osseointegration: physical and chemical considerations. Adv Clin Exp Med 2018;27(8):1055-1059

20 Safi IN, Hussein BMA, Al-Shammari AM. Testing and characterization of sintered $\beta$-tricalcium phosphate coat upon zirconia dental implant using Nd:YAG laser. J Laser Appl 2019;31(3):032002

21 Al-Sayed Ali SR, Hussein AH, Nofal AA, Hasseb Elnaby SEI, Elgazzar HA, Sabour HA. Laser powder cladding of Ti-6Al-4V $\alpha /$ Balloy. Materials (Basel) 2017;10(10):1178

22 Singh R, Tolouei R, Tan CY, et al. Sintering of hydroxyapatite ceramic produced by wet chemical method. Adv Mat Res 2011;264-265:1856-1861

23 Urquia Edreira ER, Wolke JG, Aldosari AA, et al. Effects of calcium phosphate composition in sputter coatings on in vitro and in vivo performance. J Biomed Mater Res A 2015;103(1):300-310

24 Taylor MP. Assessment of plasma-sprayed hydroxyapatite coatings. [Dissertation]. Birmingham University; 1998

25 Cheng GJ, Pirzada D, Cai M, Mohanty P. Bioceramic coating of hydroxyapatite on titanium substrate with Nd-YAG laser. Mater Sci Eng 2005;25(4):541-547

26 Kim H, Camata RP, Lee S, et al. Calcium Phosphate Bioceramics with Tailored Crystallographic Texture for Controlling Cell Adhesion. MRS Proceedings, Vol. 925. 2011

27 Thirumalai J, Hydroxyapatite: Advances in Composite Nanomaterials, Biomedical Applications and Its TechnologicalFacets, SASTRA University, IntechOpen; 2018

28 Saidi R, Fathi MH, Salimijazi H. Fabrication and characterization of hydroxyapatite-coated forsterite scaffold for 
tissue regeneration applications. Bull Mater Sci 2015;38(5): 1367-1374

29 Klein CP, Wolke JG, de Blieck-Hogervorst JM, de Groot K. Features of calcium phosphate plasma-sprayed coatings: an in vitro study. J Biomed Mater Res 1994;28(8):961-967

30 Sugiyama T, Miake Y, Yajima Y, Yamamoto K, Sakurai K. Surface observation of thin hydroxyapatite-coated implants at 80 months after insertion.J Oral Implantol 2011;37(2):273-278

31 Ozeki K, Okuyama Y, Fukui Y, Aoki H. Bone response to titanium implants coated with thin sputtered HA film subject to hydrothermal treatment and implanted in the canine mandible. Biomed Mater Eng 2006;16(4):243-251

32 Katto M, Ishibashi K, Kurosawa K, et al. Crystallized hydroxyapatite coatings deposited by PLD with targets of different densities. J Phys Conf Ser 2007;59:75-78

33 Chung SH, Kim HK, Shon WJ, Park YS. Peri-implant bone formations around $(\mathrm{Ti}, \mathrm{Zr}) \mathrm{O}(2)$-coated zirconia implants with different surface roughness. J Clin Periodontol 2013;40(4):404-411

34 Eom T-G, Jeon GR, Jeong CM, et al. Experimental study of bone response to hydroxyapatite coating implants: bone-implant contact and removal torque test. Oral Surg Oral Med Oral Pathol Oral Radiol 2012;114(4):411-418
35 Rong M, Zhou L, Gou Z, Zhu A, Zhou D. The early osseointegration of the laser-treated and acid-etched dental implants surface: an experimental study in rabbits. J Mater Sci Mater Med 2009;20(8):1721-1728

36 Khan SP, Auner GG, Newaz GM. Influence of nanoscale surface roughness on neural cell attachment on silicon. Nanomedicine 2005;1(2):125-129

37 Ward BC, Webster TJ. The effect of nanotopography on calcium and phosphorus deposition on metallic materials in vitro. Biomaterials 2006;27(16):3064-3074

38 Tanimoto Y, Nishiyama N. Preparation and physical properties of tricalcium phosphate laminates for bone-tissue engineering. J Biomed Mater Res A 2008;85(2):427-433

39 Chien CS, Han TJ, Hong TF, Kuo TY, Liao TY. Effects of different hydroxyapatite binders on morphology, Ca/P ratio and hardness of Nd-YAG laser clad coatings. Mater Trans 2009;50:2852-2857

40 Safi IN, Mohammed Ali Hussein B, Al-Shammari AM. In vitro periodontal ligament cell expansion by co-culture method and formation of multi-layered periodontal ligament-derived cell sheets. Regen Ther 2019;11:225-239 